Check for updates

Cite this: RSC Adv., 2018, 8, 34718

\title{
Synthesis of gamma radiation-induced PEGylated cisplatin for cancer treatment $\dagger$
}

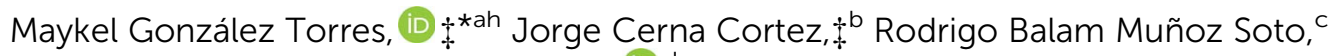 \\ Alfonso Ríos Perez, ${ }^{c}$ Heriberto Pfeiffer, (D) ${ }^{\mathrm{d}}$ Gerardo Leyva Gómez, ${ }^{\mathrm{e}}$ Joaquín Zúñiga \\ Ramos $^{f}$ and Ana Leonor Rivera (D) $* g$
}

\begin{abstract}
The use of poly(ethylene glycol) (PEG) for the development of novel PEGylated biomolecules is playing an increasingly meaningful role in cancer treatment. Cisplatin (CDDP), is a useful chemotherapy drug. However, it is unclear whether PEGylated cisplatin (CDDPPEG) has potential as an alternative therapeutic agent. Here we prepared a PEGylated cisplatin by gamma radiation-induced synthesis, for the first time. PEGylated drugs were characterized using Raman and Fourier transform infrared spectroscopy (FTIR), as well as scanning electron microscopy coupled with Energy Dispersive X-ray (SEM/EDX). The results show that the cisplatin can be successfully PEGylated by this method. Furthermore, we show a proposal for the mechanism of the PEGylation reaction. The novel product exhibits in vitro therapeutic potential comparable to cisplatin at concentrations lower than $23 \mu \mathrm{M}(\mathrm{Pt})$, causing differences in cell cycle checkpoints, which suggest changes in the signaling pathways that control growth arrest and cause apoptosis of A549 cells.
\end{abstract}

Received 25th July 2018

Accepted 29th September 2018

DOI: 10.1039/c8ra06296j

rsc.li/rsc-advances attachment to bioactive macromolecules and small substances (PEGylation). ${ }^{6}$

The use of PEG as a crowding agent allows the modification of peptides, ${ }^{7}$ proteins,${ }^{8}$ oligonucleotides, ${ }^{9}$ small organic molecules and drugs. ${ }^{10}$ Consequently, PEGylation is increasingly used in research aiming at the discovery of novel bioactive substances that might become new paradigms for specific therapies. ${ }^{\mathbf{1 1 , 1 2}}$

Therefore, the growing success of PEGylation is due to its advantages, such as the ability to prepare PEG-biomolecule conjugates with prolonged residence within the body (longer half-life), ${ }^{13}$ or protein-based pharmaceuticals with improved pharmaco-dynamics (PD) and pharmaco-kinetics (PK), decreased degradation by proteolytic enzymes, and increased thermal stability. ${ }^{\mathbf{1 4}}$ However, the attachment of the polymer to a protein or a small drug can also bring shortcomings such as reductions in biological potency because of steric entanglement after covalent attachment. ${ }^{15}$

Early studies were focused on PEGylation of proteins, peptides or non-peptide molecules and enzymes, ${ }^{\mathbf{1 6}}$ but recent research into PEGylated macromolecules and small drugs has continuously increased as a means to overcome the instability, high toxicity, untargeted biodistribution, rapid excretion or low solubility of some pharmaceuticals. ${ }^{17}$

PEGylation has also played a significant role in anti-cancer therapy, since the therapeutic efficacy of low molecular weight drugs can be improved by passive or active targeting. ${ }^{18}$ An example of this is cisplatin, which is a chemotherapy and cytotoxic drug widely used for the treatment of cancer. ${ }^{\mathbf{1 9 2 0}}$ 
Nevertheless, the use of cisplatin is hampered by its short halflife and toxicity towards healthy cells and tissues. ${ }^{21,22}$

The cisplatin therapeutic index can be increased with the synthesis of targeted models. ${ }^{23}$ Previous studies have alluded to the effect of surface PEG density on the loading and release of cisplatin from nanoparticles, and to the greater antitumor activity of cisplatin-incorporated micellar formulations. ${ }^{24} \mathrm{~A}$ starshaped copolymer bearing PEG was also created as a carrier of cisplatin. ${ }^{25}$

However, a lack of research concerning the direct PEGylation of cisplatin prompted us to perform a thorough investigation. Two important questions are whether cisplatin can be attached covalently to poly(ethylene glycol) and what method would be suitable to obtain the desired product. To date, the PEGylation of small drugs has been limited to the use of methoxy-PEG (mPEG) and PEG derivatives ${ }^{26}$ (i.e. PEGylated polypeptides, PEG-based hydrogels, PEG-modified liposomes), which have many shortcomings such as the undesired presence of PEG diol, crosslinking, and inactive aggregates. ${ }^{27}$

Here we describe for the first time a simple novel chemical method that aims to avoid these problems by direct PEGylation of cisplatin without the use of PEG derivatives. Our strategy relies on the use of ${ }^{60} \mathrm{Co}$ gamma radiation energy to covalently attach the PEG to the drug. Small-molecule modification has come to the fore as a novel Frontier technology. ${ }^{28}$ Gamma radiation-induced PEGylated cisplatin structure, the first of this kind, to our knowledge, showed us an inventive route for the synthesis of viable and innovative PEGylated small drugs. Firstly, we demonstrated that PEGylated cisplatin can be successfully obtained by the gamma radiation approach, and structurally characterized the modified cisplatin. Finally, we reported a proposal for the PEGylation mechanism and evaluated the in vitro therapeutic potential of the drugs.

\section{Experimental}

\subsection{Synthesis of radiation-induced PEGylated cisplatin}

cis-Diammineplatinum(II) dichloride (cisplatin) was purchased from Sigma (Lot \# MKBT4784V, St Louis, MO, USA). Doubledistilled water was used to prepare a $1000 \mathrm{ppm}$ solution of cisplatin. We used glass ampoules without vacuum, which contained approximately $2 \mathrm{~mL}$ of the prepared cisplatin solution and $1 \mathrm{~mL}$ of PEG solution. The average molecular weight of the PEG was also varied. We prepared solutions of roughly $1.5 \mathrm{~g}$ of the polymer in $80 \mathrm{~mL}$ of water with PEG of 400, 1000, 3500, and 4000 Da, namely G1, G2, G3 and G4 respectively. The synthesis of gamma radiation-induced PEGylated cisplatin was achieved via the simultaneous irradiation method, where both materials, cisplatin and PEG, are subjected to the source of ${ }^{60} \mathrm{Co}-\gamma$-radiation in air (Gamma Beam 651 PT, Nordion International). We used a dose rate of approximately $2 \mathrm{kGy} \mathrm{h}^{-1}$ and doses of 5 (D1), 10 (D2), 15 (D3), 20 (D4) and 25 (D5) kGy (measured with a Fricke dosimeter). Freeze-thaw cycles, consisting of $15 \mathrm{~min}$ of freezing in liquid nitrogen followed by $2 \mathrm{~h}$ of thawing, were used to eliminate the air in the solutions before radiation. The samples were labelled as M1G1D1, M1G1D2, M1G1D3, M1G1D4, M1G1D5, M1G2D5, M1G3D5, and M1G4D5, where M1 is assigned to cisplatin, while G and D represent the variations in the molecular weight of PEG and the doses, respectively. For instance, M1G1D2 stands for cisplatin PEGylated with PEG of $400 \mathrm{Da}$ at $10 \mathrm{kGy}$. For biological experiments, we used a buffer solution $(\mathrm{pH}=10)$ prepared with $1 \mathrm{mg} \mathrm{mL}^{-1}$ of cisplatin, $1 \mathrm{mg} \mathrm{mL}^{-1}$ mannitol, and $9 \mathrm{mg} \mathrm{mL}^{-1}$ sodium chloride in water for injection (Blastolem RU®). 1 mL of PEG was added to the buffer $(50 \mathrm{~mL})$. The sealed ampoule was treated with a dose of $10 \mathrm{kGy}$ and dose rate of approximately $1.47 \mathrm{kGy} \mathrm{h}^{-1}$.

\subsection{Raman spectroscopy}

Raman spectroscopy was performed at room temperature in a micro-Raman spectrometer (Bruker Senterra, model 910, MA, USA) equipped with a $785 \mathrm{~nm}$ laser light source. We placed the samples on a flat and clean brass plate to avoid any interference between the support and the product signals.

\subsection{Statistical analysis}

The data from this work are reported as mean \pm standard deviation and the statistical analyses were conducted using oneway analysis of variance (ANOVA) and Student's $t$-test. $P$ values $<$ 0.05 were considered as statistically significant $(n=15$ for cell viability; $n=10$ for mechanical tests). The PEGylation of cisplatin, characterization and drug release studies were carried out in triplicate.

\subsection{Cell culture}

Cells A549 (ATCC® CCL-185 ${ }^{\mathrm{TM}}$ ) grown to approximately 80\% confluency in Dulbecco's modified Eagle's medium (DMEM, GE Healthcare) containing $10 \%$ fetal bovine serum and $100 \mathrm{mg}$ $\mathrm{mL}^{-1}$ of gentamicin, streptomycin and penicillin at $37^{\circ} \mathrm{C}$ under $5 \% \mathrm{CO}_{2}$ were used for viability analysis.

\subsection{Viability analysis}

For MTT [3-(4,5-dimethylthiazolyl-2)-2,5-diphenyltetrazolium bromide (Sigma Aldrich Chemicals)] reduction assay (Mosmann, 1983), cells (5000 cells per $\mathrm{cm}^{2}$ ) were seeded on $96-w e l l$ plates in $200 \mu \mathrm{L}$ of culture media and incubated at $37{ }^{\circ} \mathrm{C}$ in $5 \%$ $\mathrm{CO}_{2}$. Under these conditions, cell's plates did not reach confluence in $96 \mathrm{~h}$. Cells were treated with increasing concentrations of cisplatin and PEGylated cisplatin $(0,10,30,50$ and 80 $\mu \mathrm{M}$; or $0,8,23,39$ and $62 \mu \mathrm{M}(\mathrm{Pt}))$. Culture medium was aspirated after treatment, and cells were analyzed in triplicates at indicated times $(0,24,48$ and $72 \mathrm{~h})$. Then, $40 \mu \mathrm{L}$ of MTT labeling mixture $\left(0.5 \mathrm{mg} \mathrm{mL}^{-1}\right)$ was added to each well, and the samples were incubated $4 \mathrm{~h}$ at $37{ }^{\circ} \mathrm{C}$ in $5 \% \mathrm{CO}_{2}$. An isopropanol: $\mathrm{HCl}$ $0.04 \mathrm{M}$ solution was added to lyse the cells and to solubilize the colored crystals. The optical density of the samples was determined at $590 \mathrm{~nm}$ using an ELISA plate reader Varioskan (Thermo, USA).

\subsection{Apoptotic, viability and cell cycle analysis by flow cytometry}

Analysis of cell death was carried out with cultures of A549 (ATCC® CCL-185 ${ }^{\mathrm{TM}}$ ) cell line, incubated for 48 and 72 hours in 
the absence or in the presence of increasing concentrations of cisplatin and PEGylated cisplatin (50 and $80 \mu \mathrm{M}$; or 39 and 62 $\mu \mathrm{M}(\mathrm{Pt})$ ). Apoptotic cells were analyzed using the Muse ${ }^{\mathrm{TM}}$ Count, Viability kit, Muse ${ }^{\mathrm{TM}}$ Caspase 3/7 kit and the Muse ${ }^{\mathrm{TM}}$ Annexin V and Dead Cell Assay kit (Muse ${ }^{\mathrm{TM}}$ Cell Analyzer; Millipore, Billerica, MA, USA). Cell cycle analysis was performed by using the Muse $^{\mathrm{TM}}$ Cell Cycle Kit according to manufacturer's instructions at two concentrations of Cisplatin and CDDPPEG. We obtained the percentage of viable, dead, apoptotic, G1, S and G2/M cells.

\section{Results and discussion}

\subsection{Raman characterization}

Fig. 1A shows the Raman spectrum of solid dried cisplatin (see structure 1). We observed the amine symmetric and asymmetric stretching vibration $(\nu(\mathrm{NH}))$ at $3295 \mathrm{~cm}^{-1}$ and $3211 \mathrm{~cm}^{-1}$, in the region of $3000-3500 \mathrm{~cm}^{-1}$. The group of bands at $1646 \mathrm{~cm}^{-1}$, $1539 \mathrm{~cm}^{-1}, 1310 \mathrm{~cm}^{-1}$ is assigned to the amine in-plane bend $(\delta(\mathrm{N}-\mathrm{H}))$, while the band at $813 \mathrm{~cm}^{-1}$ is ascribed to the amine out-of-plane bend $\left(\delta_{\mathrm{p}}(\mathrm{N}-\mathrm{H})\right){ }^{29}$ Four other strong bands at $523 \mathrm{~cm}^{-1}, 317 \mathrm{~cm}^{-1}, 248 \mathrm{~cm}^{-1}$ and $157 \mathrm{~cm}^{-1}$, are attributed to symmetric $\nu_{\mathrm{s}}(\mathrm{Pt}-\mathrm{N})$, asymmetric stretching vibration $\nu_{\mathrm{a}}(\mathrm{Pt}-\mathrm{Cl})$, $\mathrm{N}-\mathrm{Pt}-\mathrm{N}$, and $\mathrm{Cl}-\mathrm{Pt}-\mathrm{Cl}$ bending vibrations respectively. ${ }^{30}$ Aqueous cisplatin $\left(1 \mathrm{mg} \mathrm{mL} \mathrm{m}^{-1}\right.$ ) was also surveyed by FT-Raman (Fig. 1B) spectroscopy. As can be seen, two regions were studied, namely, the amplified region at $200-800 \mathrm{~cm}^{-1}$, and the broad region at $800-3000 \mathrm{~cm}^{-1}$. The amplified region revealed that the weak bands at $222 \mathrm{~cm}^{-1}(\delta(\mathrm{Cl}-\mathrm{Pt}-\mathrm{Cl})), 286 \mathrm{~cm}^{-1}(\delta(\mathrm{N}-\mathrm{Pt}-\mathrm{N}))$, and $336 \mathrm{~cm}^{-1}(\nu(\mathrm{Pt}-\mathrm{Cl}))$ decreased in intensity with respect to the corresponding bands of solid dried cisplatin, probably as a consequence of the cis-DDP hydrolysis. ${ }^{31}$ The weak $\nu_{\mathrm{s}}(\mathrm{Pt}-\mathrm{N})$ band shifted to $490 \mathrm{~cm}^{-1}$ and the new band at $385 \mathrm{~cm}^{-1}$ was associated with $\nu(\mathrm{Pt}-\mathrm{O})$ (see structure 2 in Fig. 1B).

We assigned the bands appearing at around $743 \mathrm{~cm}^{-1}$ to the amine out-of-plane bend (Fig. 1B). It is also of interest to note the new band at $1041 \mathrm{~cm}^{-1}$, which corresponded to the stretching vibration of $\mathrm{PtOH}(\nu(\mathrm{Pt}-\mathrm{O})) .{ }^{32}$ The most striking difference of this spectrum is the increasing band intensity (1332, 1515 and $\left.1660 \mathrm{~cm}^{-1}\right)$ which reveals that the $\delta(\mathrm{N}-\mathrm{H})$ activity increases due to the changes in the structure caused by the replacement of the outgoing ligands $(\mathrm{Cl}) .{ }^{33}$ As seen, the new band at $2489 \mathrm{~cm}^{-1}$ is also a product of the hydrolysis and is characteristic of new $\nu(\mathrm{NH})$. A very broad, irregular and intense signal of amine was detected over $3500 \mathrm{~cm}^{-1}$ (no shown).

On the other hand, the spectrum of PEG 400 is shown in Fig. 1C (compound 3). The most striking feature is an intense band at $2878 \mathrm{~cm}^{-1}$, which represents the stretching vibrations of the $\mathrm{CH}_{2}$ group of polyethylene glycol. ${ }^{34}$ This symmetric stretching is probably due to the overlapping with the antisymmetric stretching of the methylene group usually observed at higher frequencies (roughly $2938 \mathrm{~cm}^{-1}$ ). The rest of the bands are assigned as follows:

(a) The band at $1468 \mathrm{~cm}^{-1}$ corresponded to the antisymmetric bending mode of the $\mathrm{CH}_{2}-\mathrm{CH}_{2}$ group.

(b) The bands appearing at $1284 \mathrm{~cm}^{-1}$ and $1244 \mathrm{~cm}^{-1}$ were attributed to methylene twisting vibrations. (c) The bands observed at $1132 \mathrm{~cm}^{-1}$ and $1046 \mathrm{~cm}^{-1}$ were ascribed to skeletal vibrations.

(d) The bands at $545 \mathrm{~cm}^{-1}$ and $276 \mathrm{~cm}^{-1}$ were identified as $\mathrm{C}-\mathrm{C}-\mathrm{O}$ bending vibrations and skeletal deformation modes of the studied polyether. ${ }^{35}$

None of the bands observed in the PEG spectrum showed signals in the PEGylated cisplatin spectrum (Fig. 1D), which suggests that all the PEG molecules reacted with the CCDP drug. It is of note that the cisplatin band at $1332 \mathrm{~cm}^{-1}$ shifted to $1367 \mathrm{~cm}^{-1}$, the band at $1515 \mathrm{~cm}^{-1}$ disappeared in CDDPPEG, and the band at $1660 \mathrm{~cm}^{-1}$ was also shifted to $1631 \mathrm{~cm}^{-1}$ probably because of the chemical reaction. We could not observe signals associated with the presence of chloride of unPEGylated cisplatin molecules, which suggests that all the cisplatin had reacted and was furthermore completely hydrolyzed. The bands associated with the $\mathrm{Pt}-\mathrm{O}$ and $\mathrm{N}-\mathrm{H}$ stretching and bending vibrations of CDDP were dramatically distorted and disappeared from the spectrum of the PEGylated drug (bands at $2489 \mathrm{~cm}^{-1}, 1515 \mathrm{~cm}^{-1}, 1041 \mathrm{~cm}^{-1}$ and $743 \mathrm{~cm}^{-1}$ ).

Additionally, a new broad band within the range of 2125$1800 \mathrm{~cm}^{-1}$ was detected. This signal was associated with hydrogen bonds related to the presence of a carbonyl group. ${ }^{36}$ The unusually high carbonyl frequency is probably owing to the influence of electronegative substituents in the carbon atom. The signal was not observed at increasing doses, which indicates CDDPPEG is going through complete hydrolysis. Based on these experimental results, we have suggested a structure as shown in Fig. 1D (compound 4), which will be hereafter discussed in the context of the proposed mechanism of the PEGylation reaction. It was also observed that an increase in the radiation dose tended to increase the intensity of the three bands. However, this tendency was unclear when doses of 15 and 25 kGy were used because the bands decreased in intensity with respect to $5 \mathrm{kGy}$ sample (Fig. 1E). This indicates that the concentration of the PEGylated molecules does not depend only on the radiation dose, but also about the types of PEGylated molecules that are formed. On the other hand, an increase in the molecular weight of the PEG increased the band intensity with respect to PEG400 (G1) (Fig. 1F). Nevertheless, the G4 molecular weight did not follow the increasing intensity trend, probably because of radiolytic degradation of PEG. ${ }^{35}$

It was concluded that a novel CDDPPEG molecule was successfully synthesized. The spectra of the products contain: an overlapping contribution of $\mathrm{Pt}(\mathrm{OH})$ stretching vibrations that reveals a wider and less intense band relative to CDDP (see Fig. 1D); the bending vibration of the amine group $\delta(\mathrm{N}-\mathrm{H})$ as a consequence of the replacement of multiple outgoing chloride ligands; and also, a novel carbonyl group region presumably obtained in the process of covalent attachment of PEG onto cisplatin. We obtained additional evidence of the synthesis and the presence of the carbonyl group from SEM, FTIR, EDX and UV survey (Fig. S1-S4†). SEM image of the sample revealed that clusters of small particles of roughly $50 \mathrm{~nm}$ in diameter were formed (Fig. S1 $\dagger$ ). FTIR confirmed the presence of a carbonyl stretching vibration at $1728 \mathrm{~cm}^{-1}$ (Fig. S2 $\dagger$ ).

Energy-dispersive X-ray spectroscopy corroborated the presence of platinum, carbon, oxygen, nitrogen, and even 

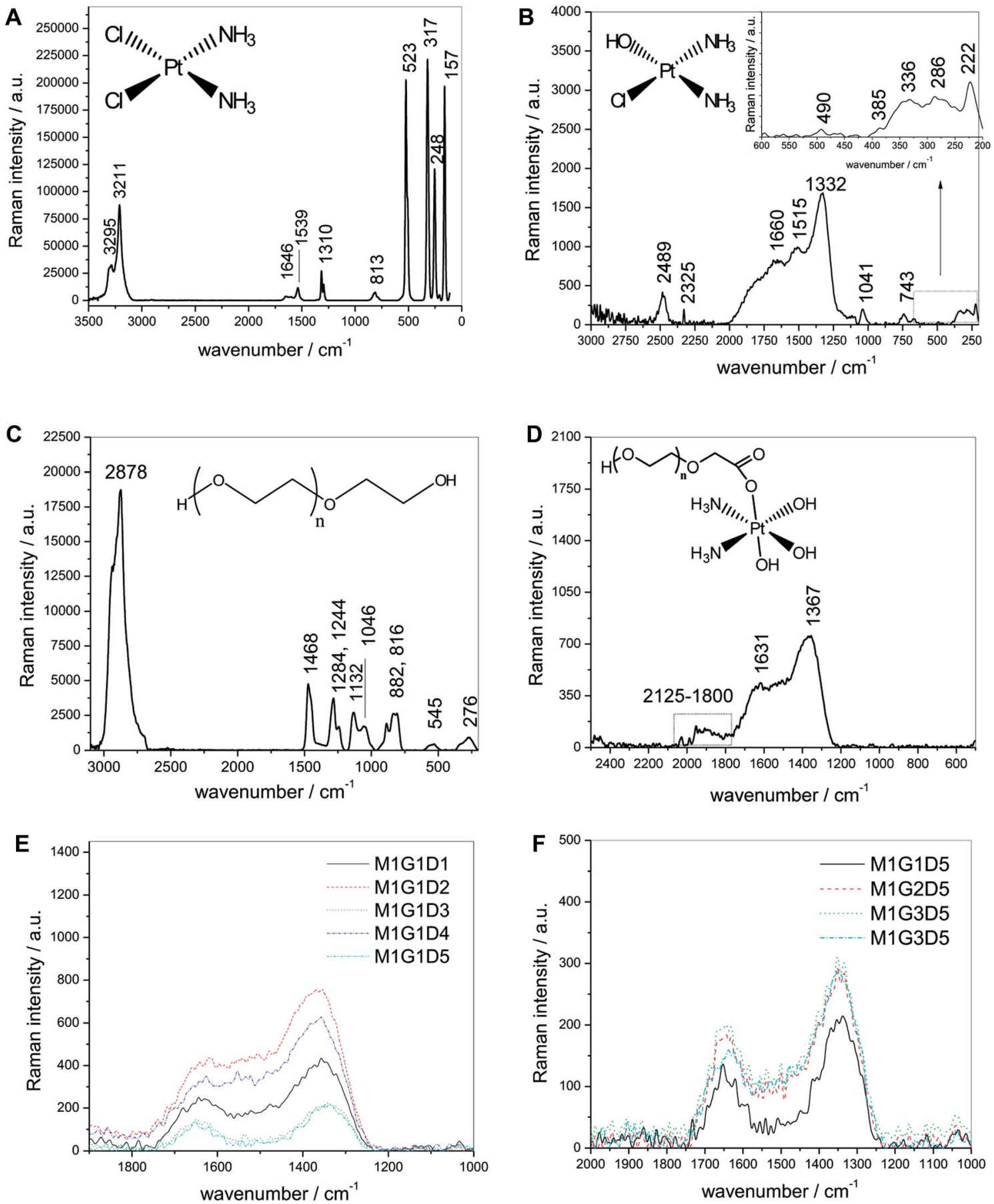

Fig. 1 (A) Raman spectrum of pure solid cisplatin in the region $3500-50 \mathrm{~cm}^{-1}$. (B) Raman spectrum of aqueous cisplatin in distilled water (1 mg $\mathrm{mL}^{-1}$ ). (C) Raman spectrum of aqueous polyethylene glycol (400 Da). (D) Raman spectrum of radiation-induced PEGylated cisplatin (M1G1D1). (E) Raman spectra of the effect of different doses on the synthesis of PEGylated cisplatin (F) Raman spectra of the effect of different PEG molecular weights (G1, G2, G3, G4 and G5) on the synthesis of PEGylated cisplatin.

chlorine peaks (Fig. S3†). UV analysis showed a new band at $206 \mathrm{~nm}$ likewise attributed to this group (Fig. S4†). ${ }^{37-39}$ It also allowed to estimate the mean lifetime of PEGylated cisplatin. These results provided evidence that the attachment of PEG to the drug defines a delay in the release process in vitro ${ }^{31}$ (Fig. S5-S7†).

\subsection{Proposed mechanism of PEGylation of cisplatin}

Here, we propose a mechanism for the preparation of gamma radiation-induced PEGylated cisplatin. The synthesis is carried out in double-distilled water; consequently, the absorption of high-energy radiation by water is of concern. Initially, the gamma photons ionize water molecules, which produce 
secondary electrons with enough energy to ionize further molecules and thus to form clusters of ions (spurs). Then, the ionized molecules can also undergo excitation or thermal transfer, depending upon the amount of energy that is transferred to the solvated electron.

The passage of the modified electron creates well-known species, namely a radical ion, a free sub-excited electron and an excited water molecule (see eqn (1)-(3)), which can diffuse and further react with other molecules (initiation reaction).

$$
\begin{gathered}
\mathrm{H}_{2} \mathrm{O} \stackrel{\text { gamma radiation }}{\longrightarrow} \mathrm{H}_{2} \mathrm{O}^{\bullet+}+\mathrm{e}^{-} \\
\mathrm{H}_{2} \mathrm{O} \stackrel{\text { gamma radiation }}{\longrightarrow} \mathrm{H}_{2} \mathrm{O}^{*} \\
\mathrm{e}^{-} \stackrel{\text { gamma radiation }}{\longrightarrow} \mathrm{e}_{\mathrm{ac}}{ }^{-}
\end{gathered}
$$

The radical ions of water $\left(\mathrm{H}_{2} \mathrm{O}^{\cdot+}\right)$ can dissociate and the excited water molecules $\left(\mathrm{H}_{2} \mathrm{O}^{*}\right)$, can dissipate their excess energy to produce hydroxyl radicals and a hydrogen ion (eqn (4) and (5), propagation reactions)

$$
\begin{gathered}
\mathrm{H}_{2} \mathrm{O}^{\cdot+} \rightarrow \mathrm{H}^{+}+\dot{\mathrm{O}} \mathrm{H} \\
\mathrm{H}_{2} \mathrm{O}^{*} \rightarrow \dot{\mathrm{H}}+\dot{\mathrm{O}} \mathrm{H}
\end{gathered}
$$

Hydrogen peroxide can be obtained by the radical coupling reaction of hydroxyl radicals (eqn (6), termination reaction of interest with formation of a molecular product)

$$
2 \dot{\mathrm{OH}} \rightarrow \mathrm{H}_{2} \mathrm{O}_{2}
$$

To summarize, the complex radiolysis of water can be represented by the following products (eqn (7)):

$$
\mathrm{H}_{2} \mathrm{O} \stackrel{\text { gamma radiation }}{\longrightarrow} \mathrm{e}_{\mathrm{ac}}{ }^{-}, \dot{\mathrm{H}}, \dot{\mathrm{O}}, \dot{\mathrm{O}} \mathrm{H}, \mathrm{H}_{\mathrm{ac}}{ }^{+}, \mathrm{H}_{2}, \mathrm{H}_{2} \mathrm{O}_{2}
$$

The presence of $\mathrm{H}_{2} \mathrm{O}_{2}$ in the radiolysis of water is of note; it is produced mostly in the spurs. We propose the reaction of cisplatin with hydrogen peroxide to produce diaminetetrahydroxyplatinate (Iv) ${ }^{\mathbf{4 0}}$ (as in compound $\mathbf{5}$ ). The latter molecule can be excited by gamma radiation to produce a cisplatinum(Iv) diammintetrahydroxyl intermediate radical (such as precursor 7) and hydrogen. Meanwhile, PEG is probably degraded by gamma radiation to yield PEG oligomers. The terminal hydrogen of PEG oligomers can be removed by the hydrogen peroxide, and consequently; a double bond is formed to yield an aldehyde (oxidation reaction). The aldehyde hydrogen is probably abstracted by radiation to form a carbonyl radical (for example, radical 11). We suggest a termination reaction between the cisplatinum(Iv) diammintetrahydroxyl and the aldehyde radical via a coupling reaction to yield the diaminetrihydroxy-1-oxo-polyoxyethylene-platinate(Iv) (PEGylated cisplatin, such as compound 4). Finally, we show how the new structure could cleave with a nucleobase (guanine) leading to intra-strand or inter-strand cross-linked adducts (such as 13, 14 and 15) because two hydroxyl groups must be cleaved. ${ }^{\mathbf{4 1}}$ The proposed mechanism does not restrict the attachment of PEG to the alpha alcohol of diaminetetrahydroxyplatinate(Iv) - the four hydroxyl groups are available for reaction, and more than one PEG molecule can be attached with diverse molecular weights, thus evidencing the complexity of this reaction. The oxidation reaction of cisplatin to yield platinum(Iv) tetrahydroxo compounds is supported by the literature. ${ }^{42}$ This reaction probably requires a certain degree of heat to obtain the desired product. The temperature of the water is proportional to the internal kinetic energy of the water molecules. ${ }^{60} \mathrm{Co}-\gamma$-rays are photons, which do not have a temperature, but provide enough energy to the system to contribute towards an increase in the temperature inside the ampoules. Excess energy is partially used to form the spurs and is also employed in the oxidation reactions that involve creating new bonds, as well as in the radiolytic degradation of $\mathrm{PEG}$.

PEGylation was performed with cisplatin purchased from Sigma Aldrich (dissolved in distilled water, $\mathrm{pH}=7$ ) and with injectable cisplatin $(\mathrm{pH}=10)$. An increase in the precipitate was observed at $\mathrm{pH}=7$. The results imply that $\mathrm{pH}$ influences the obtaining of PEGylated cisplatin. We propose that the presence of the basic buffer in the injectable solution displaces the reaction to the formation of diaminetetrahydroxyplatinate(Iv) (as in compound 5), while the absence of a basic buffer $(\mathrm{pH} \leq 7)$ could displace the reaction to the formation of oxoplatin (see compound 16). An alternative route of PEGylated cisplatin is

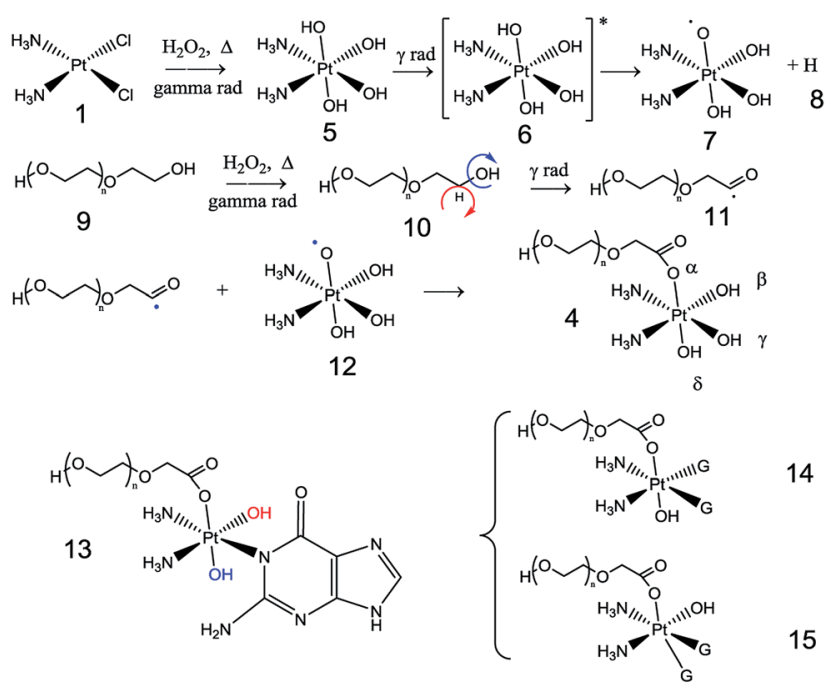

alternative route
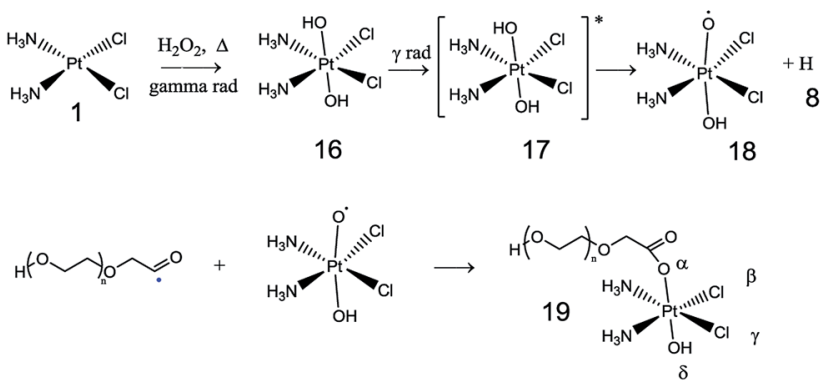

Fig. 2 Proposed mechanism of gamma radiation-induced PEGylated cisplatin/adduct formation ( $G=$ guanine). 
proposed in Fig. 2, which involves the formation of an excited state of oxoplatin (such as precursor 17), to yield a cisplatinu$\mathrm{m}$ (Iv) diammin-dichloro-dihydroxyl intermediate radical. The intermediate reacts with radical $\mathbf{1 1}$ to obtain diamine-1-oxopolyoxyethylene-2,3-dichloro-4-hydroxy-platinate(Iv) (PEGylated cisplatin, such as compound 19). As seen, the proposed structure (compound 18) can only be PEGylated at the alpha and delta positions because the beta and gamma positions are occupied by the chlorine ligands (in acidic media). The proposed alternative route of synthesis of prodrug oxoplatin as precursor to obtain the conjugate PEGylated cisplatin is supported by extensive research. ${ }^{43-47}$

\subsection{Analysis of viability and cell cycle of PEGylated cisplatin}

Fig. 3A and B show the mean viability percentage following cisplatin and the PEGylated drug treatment at different concentrations versus time. For cisplatin, the viability decreased with increasing concentration compared to the untreated samples. As can be seen, it was also reduced with increasing incubation time. PEGylated cisplatin samples followed the same trend in the range $10-30 \mu \mathrm{M}$ (or $8-23 \mu \mathrm{M}(\mathrm{Pt})$ ), with similar growth inhibition. It is of note that, for $48 \mathrm{~h}(10 \mu \mathrm{M}$ (or 8 $\mu \mathrm{M}(\mathrm{Pt}))$, the viability is higher in cisplatin compared with PEGylated samples, which indicates that CDDPPEG can be more efficient at certain concentrations and incubation times. However, over $30 \mu \mathrm{M}$ (or $23 \mu \mathrm{M}(\mathrm{Pt}))$ some inconsistencies are observed for CDDPPEG and even for CDDP, although on a lesser scale. We concluded that the modified cisplatin exhibits in vitro therapeutic potential comparable to cisplatin at low concentrations, while at higher concentration $(>30 \mu \mathrm{M}$ (or $>23 \mu \mathrm{M}$ $(\mathrm{Pt})$ )), the new substance did not alter the viability. The changes observed in CDDPPEG are probably attributed to the molecular crowding on the self-entanglement of PEGylation and served to reaffirm indirectly the synthesis.

Cell viability (\%) of the drugs for $48 \mathrm{~h}$ at different concentrations was examined. The first notable feature is the decrease of the DNA content index in CDDP at a dose of 50 and $80 \mu \mathrm{M}$ (or 39 and $62 \mu \mathrm{M}(\mathrm{Pt}))$ respect to the control sample (Fig. 4). However, this trend was not observed for CDDPPEG. That is, the decrease of percentage of live cells was more important for 30 $\mu \mathrm{M}$ (or $23 \mu \mathrm{M}(\mathrm{Pt})$ ). This result implies that the modified cisplatin requires low concentrations for therapeutic use. It is of note that the in vitro activity of CDDPPEG is not a good predictor of their potential effectiveness in vivo. ${ }^{48}$ In addition, the cellcycle analyses of control, cisplatin and PEGylated cisplatin samples for different concentrations of the drugs at 48 hours of treatment are shown in Fig. 5. The drugs present notable changes in the cell cycle checkpoints by comparison with control sample. It is well-known that in a first step, cisplatin induces a transient S-phase arrest and further cause the inhibition of Cdc2-cyclin A or B kinase, also affecting G2/M arrest. A decrease of G0/G1 values is observed from 20.0 (control) to 2.32.4 and the effect in G2/M by the increase from 23.5 to 40.8 for CDDP. PEGylated cisplatin samples show a different trend, first; the analysis depended upon the concentration of the drug, second; the G2/M arrest was similar to that shown by the control a

A549 cells treated with CDDP

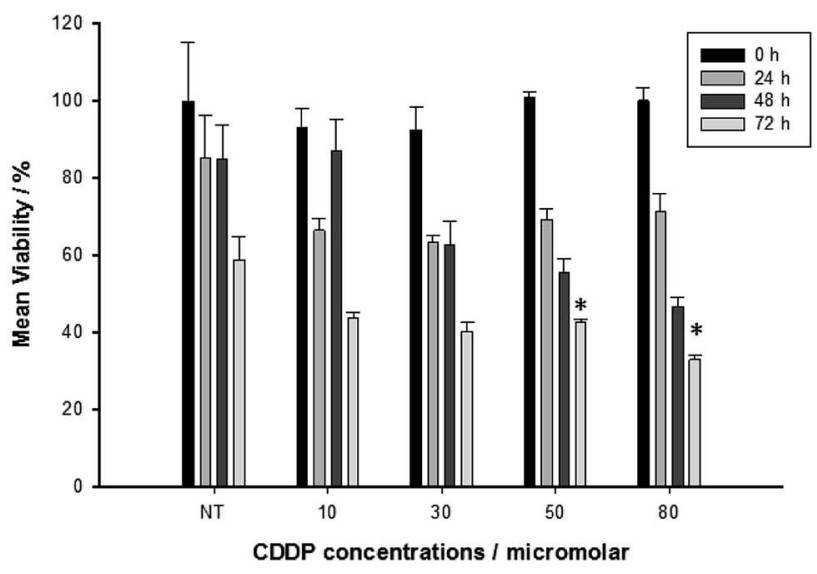

b

A549 cells treated with CDDPPEG

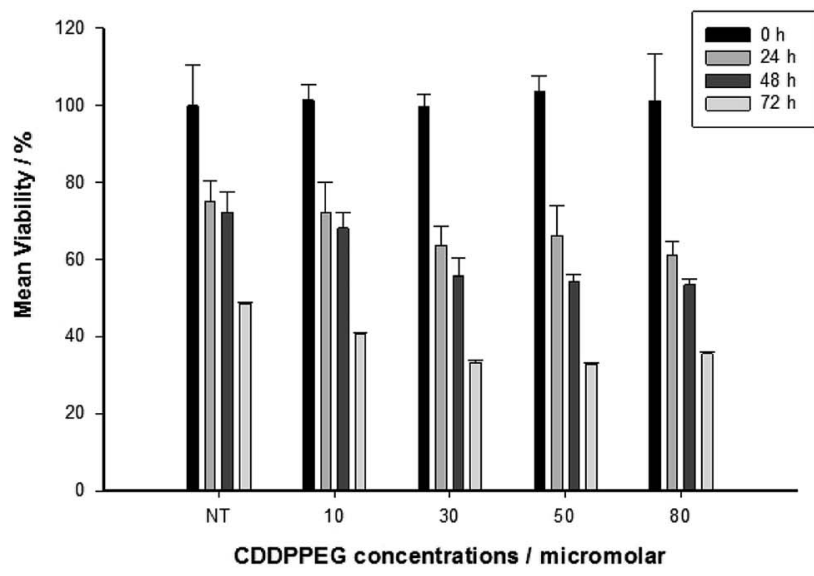

Fig. 3 CDDPPEG does not reduce cell proliferation rates over $30 \mu \mathrm{M}$ (or $23 \mu \mathrm{M}(\mathrm{Pt})$ ). A549 cells ( 4000 cells per $\mathrm{cm}^{2}$; seeded $24 \mathrm{~h}$ before the treatment starting point) were treated as indicated: NT-non-treated, (a) CDDP from 10 to $80 \mu \mathrm{M}$ (or $62 \mu \mathrm{M}(\mathrm{Pt})$ ). and (b) CDDPPEG, same concentration range. Cell viability was determined by a MTT assay. Absorbance values from non-treated cells at time zero (NT) were set as $100 \%$ for comparison purposes. Proliferation rates were measured after 24, 48, and $72 \mathrm{~h}$. Mean values and standard error ( \pm S.E.) from at least three independent experiments performed in triplicates are shown. $* P>0.05$ between non-treated and treated cells.

sample. Besides, G0/G1 values varied randomly from 20.0 (control) to 16.2; 35.8; and 13.1 and also affected on a smaller scale S-phase arrest. The results evidence that PEGylated cisplatin mechanism of cleavage with DNA is different to that of cisplatin. The variations of G0/G1 arrest influence the cytotoxicity of PEGylated samples, but their relationship still needed to be deciphered. ${ }^{49}$

\subsection{The proposed mechanism of cellular uptake}

First, the water molecule attacks the cisplatin, which releases the chloride ligand $\left(\mathrm{Cl}^{-}\right)$. In this step a diaquo intermediate is formed. However, due to the action of gamma radiations, and 


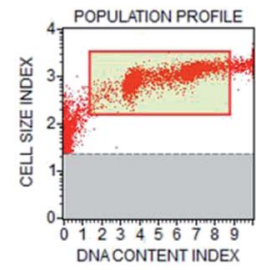

control

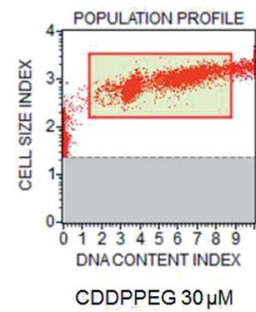

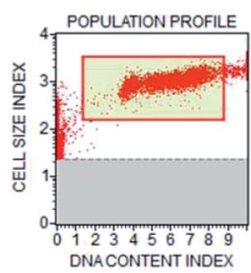

CDDP $50 \mu \mathrm{M}$

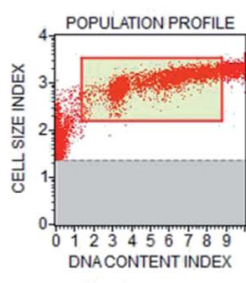

CDDPPEG $50 \mu \mathrm{M}$
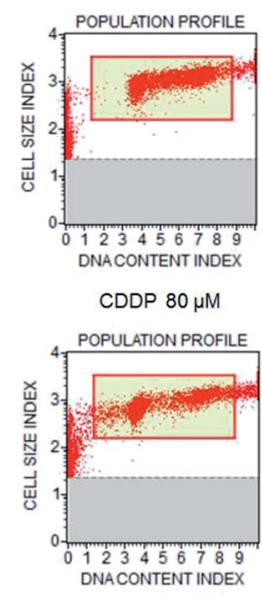

CDDPPEG $80 \mu \mathrm{M}$
CDDP $80 \mu \mathrm{M}$

Fig. 4 Cell viability profile obtained by treating A549 cells with CDDP and CDDPPEG at different concentrations (30,50 and $80 \mu \mathrm{M})$ (or 23, 39 and $62 \mu \mathrm{M}(\mathrm{Pt}))$ for $48 \mathrm{~h}$.
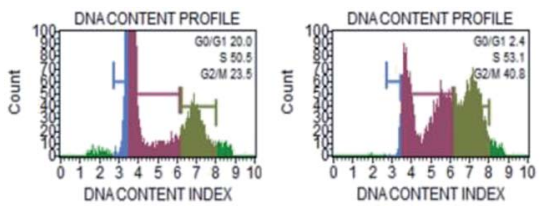

DNACONTENT INDEX

control

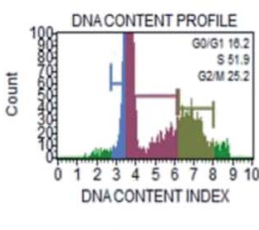

CDDPPEG $30 \mu \mathrm{M}$

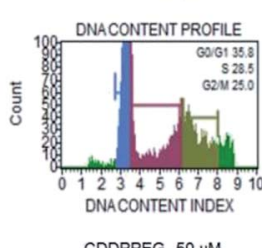

CDDPPEG $50 \mu \mathrm{M}$

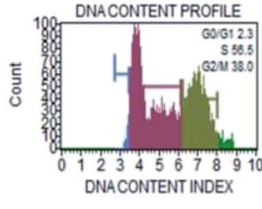

CDDP $80 \mu \mathrm{M}$

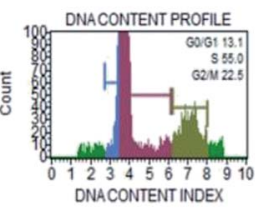

CDDPPEG $80 \mu \mathrm{M}$
Fig. 5 Cell cycle analysis obtained by treating A549 cells with CDDP and CDDPPEG at different concentrations $(30,50$ and $80 \mu \mathrm{M})(23,39$ and $62 \mu \mathrm{M}(\mathrm{Pt}))$ for $48 \mathrm{~h}$.

the presence of peroxide, the tetrahedral conformation of cisplatin is transformed into an octahedron conformation. This reaction is likeliest in basic medium (buffer). The lower $\mathrm{pH}$ inhibits the release of the chloride ligands and increase the yields of oxoplatin in the mechanism of PEGylation.

Therefore, in a basic medium, the diaminetetrahydroxyplatinate(Iv) has four hydroxyl groups to produce a tetraaquo molecule that can react with DNA. The $\left[\mathrm{Pt}\left(\mathrm{NH}_{3}\right)_{2}(\mathrm{OH})_{2}\right]^{4+}$ active specie, which has four positive charges, is attracted by the phosphate groups of DNA strands, causing an approximation of platinum and the nitrogenous base. The platinum is linked to the nitrogen 7 of guanine, which act as a nucleophile interacting with the hydroxyl group. Two water molecules are released for each attack, and a covalent bond between Pt and two atoms of nitrogen produce an adduct. The formation of adducts produce the inhibition of replication and transcription, causing the apoptosis of the cells. ${ }^{50}$

On the other hand, in an acid medium, the oxoplatin produces the PEGylated cisplatin as shown in structure 19. The PEGylated oxoplatin cannot react with DNA by the same above described mechanism because it lacks two hydroxyl groups. Nevertheless, Zhang et al. proved that some of the cellular glutathione (GSH) molecules are oxidized into glutathione disulfide (GSSG), which results in the decrease of their chelating interaction, in this case with PEGylated cisplatin. As a result, the detoxifying effect on $\mathrm{Pt}(\mathrm{II})$ is attenuated. Therefore, gamma radiation-induced PEGylated cisplatin may have an advantage for overcoming the tumor resistance compared to the unPEGylated drug. This mechanism enables the PEGylated drug to dissociate in the bio-reducing tumor intracellular environment with further induction of cell apoptosis by the liberated of pharmacologically active $\mathrm{Pt}(\mathrm{II}){ }^{47}$

\section{Conclusion}

So far, PEGylation of small drugs such as cisplatin has been limited to the use of MPEG and PEG derivatives. Thus, we could not find reports about direct PEGylation of cisplatin that could avoid the shortcomings of these methods. Here, we address this issue in an innovative way through the study of ${ }^{60} \mathrm{Co}-\gamma$ radiation-induced PEGylation of cisplatin. The results show that it is possible to covalently attach PEG to the drug using this method. Raman analysis suggested that cisplatin reacted with the polymer and was completely hydrolyzed. The presence of signals of carbonyl groups prompted us to suggest a probable structure. Nano-particles obtained in the PEGylation were analyzed by SEM coupled to EDX, which supported our structure proposal. FTIR and UV also helped to elucidate the presence of a carbonyl group in the new product. We also estimated the in vitro mean life before and after PEGylation to show that the attachment of PEG delays the release profile. This result indicates that PEGylated drug increased the bioavailability respect to cisplatin. With sufficient evidence in hand, a mechanism for the PEGylation reaction was proposed. Finally, we surveyed the cell viability and the comparative cytotoxicity of A549 cells towards the non-PEGylated and PEGylated drug. It seems that our approach is a feasible strategy for the direct attachment of PEG onto cisplatin and the novel drug appears to have similar therapeutic potential compared to the original compound in the range of $10-30 \mu \mathrm{M}$ (or 8-23 $\mu \mathrm{M}(\mathrm{Pt})$ ). However, changes obtained in the affected signaling pathways pointed to variations in the mechanism of inhibition of cell viability. Notwithstanding, PEGylated cisplatin appears to be well suited as a potential novel drug for cancer treatment. Future studies on the newly developed drug should include investigations in vivo assessing their clinical efficacy, tolerance, side effects, as well as pharmaco-dynamics and pharmaco-kinetics profiles.

\section{Conflicts of interest}

There are no conflicts to declare.

\section{Acknowledgements}

We acknowledge Carlos Raúl Magaña Zavala, Diego Armando Quiterio Vargas and Eliezer Hernández Mecinas (UNAM) for assistance with SEM images and mechanical properties of the 
scaffolds. We are also indebted to Miriam Guadalupe Bojorge, Carolina Muñoz, Susana Vargas Muñoz and Manuel Miranda for their help with UV measurements and preparation of scaffolds. This work was partially financially supported by CONACyT through Fronteras grant FC-2016-1/2277, the Universidad Nacional Autónoma de México through DGAPA-PAPIIT IV100116 and Cátedras Conacyt.

\section{References}

1 P. Grossen, D. Witzigmann, S. Sieber and J. Huwyler, J. Controlled Release, 2017, 260, 46-60.

2 K. Knop, R. Hoogenboom, D. Fischer and U. S. Schubert, Angew., Chem. Int. Ed., 2010, 49(36), 6288-6308.

3 Y. Su, P. Burnouf, K. Chuang, B. Chen, T. Cheng and S. R. Roffler, Nat. Commun., 2017, 8, 1-12.

4 A. Kolate, D. Baradia, S. Patil, I. Vhora, G. Kore and A. Misra, J. Controlled Release, 2014, 192, 67-81.

5 S. Zalipsky and J. M. Harris, ACS Symp. Ser., 1997, 680, 1-13. 6 G. Pasut and F. M. Veronese, J. Controlled Release, 2012, 161, 461-472.

7 M. J. Roberts, M. D. Bentley and J. M. Harris, Adv. Drug Delivery Rev., 2012, 64, 116-127.

8 G. Cattani, L. Vogeley and P. B. Crowley, Nat. Chem., 2015, 7, 823-828.

9 N. Shokrzadeh, A. M. Winkler, M. Dirin and J. Winkler, Bioorg. Med. Chem. Lett., 2014, 24, 5758-5761.

10 G. Pasut and F. M. Veronese, Prog. Polym. Sci., 2007, 32, 933961.

11 M. Wu, X. Guo, F. Zhao and B. Zeng, Sci. Rep., 2017, 1-11.

12 M. Babaei, M. Ardjmand, A. Akbarzadeh and A. Seyfkordi, Tissue Eng. Regener. Med., 2014, 11, 350-354.

13 I. W. Hamley, Biomacromolecules, 2014, 15, 1543-1559.

14 P. Glue, J. W. S. Fang, R. Rouzier-Panis, C. Raffanel, R. Sabo, S. K. Gupta, M. Salfi and S. Jacobs, Clin. Pharmacol. Ther., 2000, 68, 556-567.

15 S. Freitas, A. Mero and G. Pasut, Bioconjugate Chem., 2013, 24, 456-463.

16 F. M. Veronese and G. Pasut, Drug Discovery Today, 2005, 10, 1451-1458.

17 P. L. Turecek, M. J. Bossard, F. Schoetens and I. A. Ivens, J. Pharm. Sci., 2016, 105, 460-475.

18 M. S. Newman, G. T. Colbern, P. K. Working, C. Engbers and M. A. Amantea, Cancer Chemother. Pharmacol., 1999, 43, 1-7.

19 K. Liu, L. Dai, C. Li, J. Liu, L. Wang and J. Lei, Sci. Rep., 2016, 6, 29461.

20 S. Dasari and P. Bernard Tchounwou, Eur. J. Pharmacol., 2014, 740, 364-378.

21 Reactions Weekly, 1981, 24, 11-12.

22 A. Rajeswaran, A. Trojan, B. Burnand and M. Giannelli, Lung Cancer, 2008, 59, 1-11.

23 G. E. Craig, S. D. Brown, D. A. Lamprou, D. Graham and N. J. Wheate, Inorg. Chem., 2012, 51, 3490-3497.

24 R. Plummer, R. H. Wilson, H. Calvert, A. V Boddy, M. Griffin, J. Sludden, M. J. Tilby, M. Eatock, D. G. Pearson, C. J. Ottley, Y. Matsumura, K. Kataoka and T. Nishiya, Br. J. Cancer, 2011, 104, 593-598.
25 E. Stoyanova, V. Mitova, P. Shestakova, A. Kowalczuk, G. Momekov, D. Momekova, A. Marcinkowski and N. Koseva, J. Inorg. Biochem., 2013, 120, 54-62.

26 J. M. Harris and R. B. Chess, Nat. Rev. Drug Discovery, 2003, 2, 214-221.

27 J. M. Dust, Z. Fang and J. M. Harris, Macromolecules, 1990, 1500, 3742-3746.

28 W. Li, P. Zhan, E. De Clercq, H. Lou and X. Liu, Prog. Polym. Sci., 2013, 38, 421-444.

29 H. A. Tajmir-Riahi and T. Theophanides, Can. J. Chem., 1984, 62, 1429-1440.

30 M. Malik and D. Michalska, Spectrochim. Acta, Part A, 2014, 125, 431-439.

31 M. González, U. Merino, S. Vargas, F. Quintanilla and R. Rodríguez, Mater. Sci. Eng., C, 2016, 61, 801-808.

32 D. Michalska and R. Wysokiński, Chem. Phys. Lett., 2005, 403, 211-217.

33 J. D. R. P. J. S. Susan, J. Berners-Price, T. A. Frenkiel and U. Frey, J. Chem. Soc., Chem. Commun., 1992, 3-5.

34 M. Christensen, O. F. Nielsen, P. Jensen and U. Schnell, J. Mol. Struct., 2005, 735-736, 267-270.

35 J. Koenig and A. Angood, J. Polym. Sci., Part B: Polym. Phys., 1970, 8, 1787-1796.

36 P. Larkin, Infrared and Raman Spectroscopy, Principles and Spectral Interpretation, Elsevier, Oxford, 1st edn, 2011.

37 R. Raghavan, M. Burchett, J. A. Mulligan and A. Park, Drug Dev. Ind. Pharm., 2000, 26, 429-440.

38 Z. Tao, Y. Xie, J. Goodisman and T. Asefa, Langmuir, 2010, 26, 8914-8924.

39 D. Dupeyrón, M. Kawakami, A. M. Ferreira, P. R. Cáceres, J. Rieumont, R. B. Azevedo and J. C. T. Carvalho, Int. J. Nanomed., 2013, 8, 3467-3477.

40 J. Wilson and S. Lippard, Chem. Rev., 2015, 114, 4470-4495. 41 J. Kopyra, C. Koenig-Lehmann, I. Bald and E. Illenberger, Angew. Chem., Int. Ed., 2009, 48, 7904-7907.

42 L. Tschugájeff, W. Chlopin and E. Fritzmann, Z. Anorg. Allg. Chem., 1926, 151, 253-268.

43 N. Muhammad, N. Sadia, C. Zhu, C. Luo, Z. Guo and X. Wang, Chem. Commun., 2017, 53, 9971-9974.

44 Y. Shi, S. A. Liu, D. J. Kerwood, J. Goodisman and J. C. Dabrowiak, J. Inorg. Biochem., 2012, 107, 6-14.

45 H. Xiao, R. Qi, S. Liu, X. Hu, T. Duan, Y. Zheng, Y. Huang and X. Jing, Biomaterials, 2011, 32, 7732-7739.

46 H. Xiao, H. Song, Q. Yang, H. Cai, R. Qi, L. Yan, S. Liu, Y. Zheng, Y. Huang, T. Liu and X. Jing, Biomaterials, 2012, 33, 6507-6519.

47 Z. Zhang, Y. Li, J. Wan, P. Long, J. Guo, G. Chen and C. Wang, Polym. Chem., 2017, 8, 2410-2422.

48 R. Satake-Ishikawa, M. Ishikawa, Y. Okada, M. Kakitani, M. Kawagishi, S. Matsuki and K. Asano, Cell Struct. Funct., 1992, 17, 157-160.

49 B. C. Soner, H. Aktug, E. Acikgoz, F. Duzagac, U. Guven, S. Ayla, C. Cal and G. Oktem, Int. J. Mol. Med., 2014, 34, 1249-1256.

50 A.-M. Florea and D. Büsselberg, Cancers, 2011, 3, 1351-1371. 51 R. Raghavan, M. Burchett, D. Loffredo and J. A. Mulligan, Drug Dev. Ind. Pharm., 2000, 26, 429-440. 